\title{
2 The Key Role of Sulfate in the Photochemical 3 Renoxification on Real $\mathrm{PM}_{2.5}$
}

4 Fengxia Bao, $\dot{t}+\dot{t}$ Hongyu Jiang, $\dot{t}+\dot{t}$ Yue Zhang, $\dot{t}+\dot{t}$ Meng Li, $\dot{t}+\dot{t}$ Chunxiang Ye, $s$

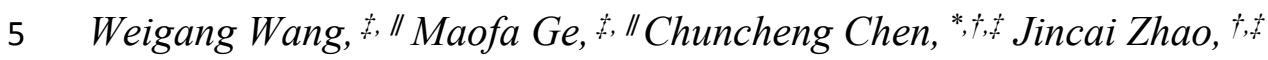

$6 \uparrow$ Key Laboratory of Photochemistry, CAS Research/Education Center for

7 Excellence in Molecular Sciences, Institute of Chemistry, Chinese Academy of

8 Sciences, Beijing, 100190, P. R. China.

$9 \quad+$ University of Chinese Academy of Sciences, Beijing, 100049, P. R. China.

$10 \S$ State Key Joint Laboratory of Environmental Simulation and Pollution Control,

11 College of Environmental Sciences and Engineering, Peking University, Beijing

$12 \quad 100871$, China

13 /" Beijing National Laboratory for Molecular Sciences (BNLMS), State Key

14 Laboratory for Structural Chemistry of Unstable and Stable Species, CAS

15 Research/Education Center for Excellence in Molecular Sciences, Institute of

16 Chemistry, Chinese Academy of Sciences, Beijing, 100190, P. R. China.

17 This SI includes a total of 7 pages (including this page) with 8 figures and 1 table. 


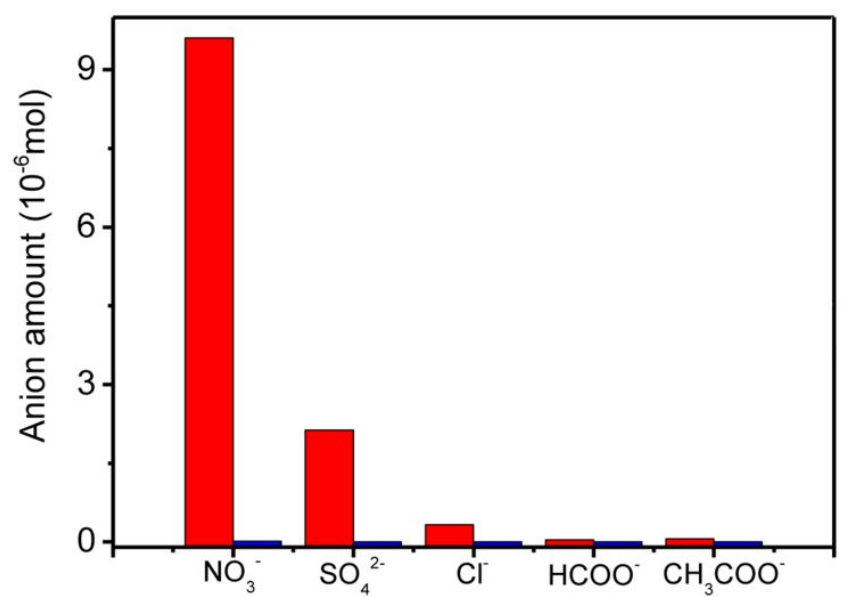

Figure S1. The amount of $\mathrm{NO}_{3}{ }^{-}, \mathrm{SO}_{4}{ }^{2-}, \mathrm{Cl}^{-}, \mathrm{HCOO}^{-}$and $\mathrm{CH}_{3} \mathrm{COO}^{-}$on $\mathrm{PM}_{2.5}$ (Sample 18-APR01) before $\left(\mathrm{PM}_{2.5}\right.$, red) and after (WISM, blue) washing with deionized water.
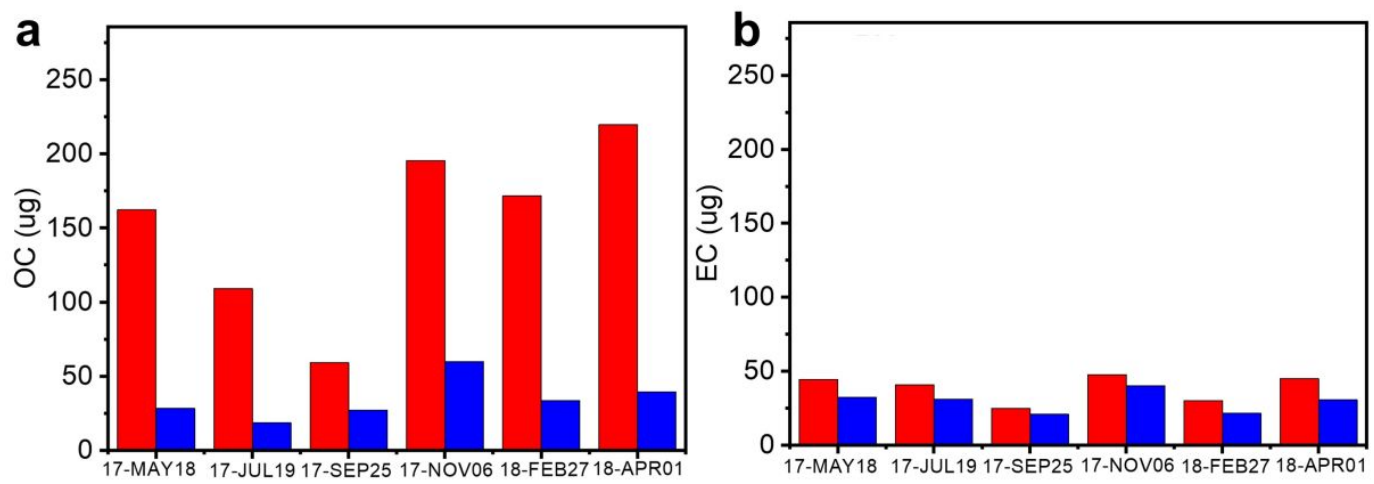

Figure S2. (a) Organic carbon (OC) and (b) elemental carbon (EC) contents of different $\mathrm{PM}_{2.5}$ samples before $\left(\mathrm{PM}_{2.5}\right.$, red) and after (WISM, blue) washing with deionized water.
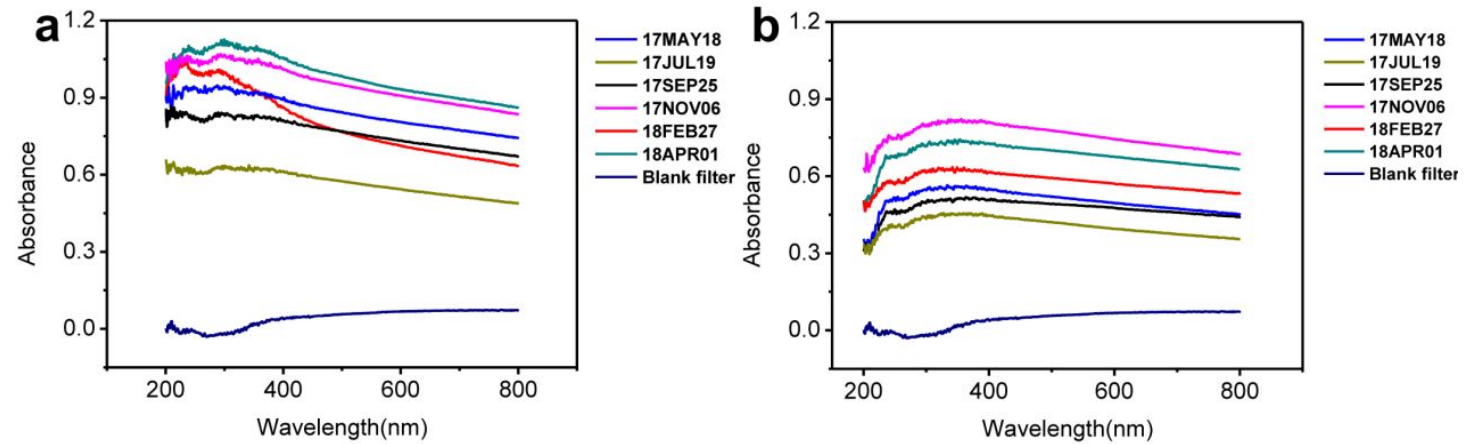
Figure S3. Diffuse reflectance UV-Vis spectra of $\mathrm{PM}_{2.5}$ samples (labeled by sampling date) before $\left(\mathrm{PM}_{2.5}, \mathrm{a}\right)$ and after (WISM, $\left.\mathrm{b}\right)$ washing with ionized water as a function of wavelength from 200 to $800 \mathrm{~nm}$. The lines in different colors represent different samples collected on different dates.
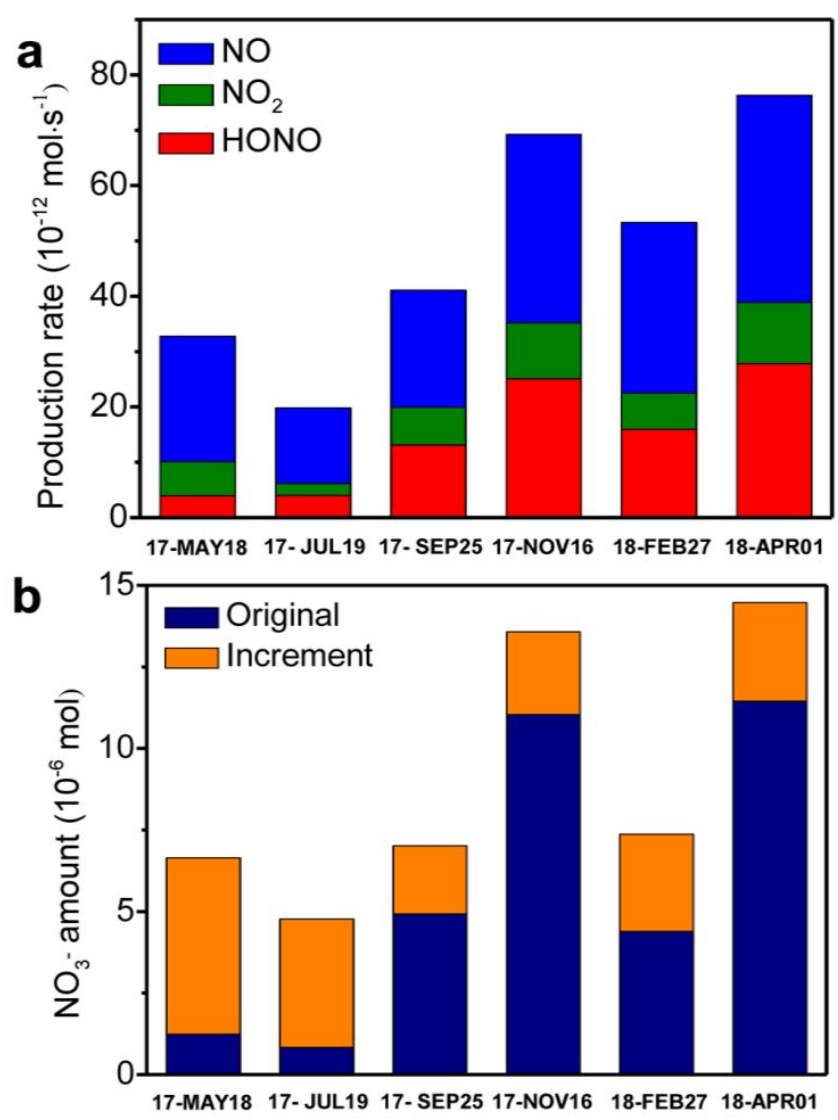

Figure S4. (a) The production rate of $\mathrm{NO}$ (blue), $\mathrm{NO}_{2}$ (green) and $\mathrm{HONO}$ (red) when $\mathrm{HNO}_{3}$ adsorbed on original $\mathrm{PM}_{2.5}$ samples (labeled by sampling date) was irradiated and (b) the original (navy) $\mathrm{NO}_{3}{ }^{-}$amount on different $\mathrm{PM}_{2.5}$ samples and the $\mathrm{NO}_{3}{ }^{-}$ increase (orange) after $\mathrm{HNO}_{3}$ adsorption. 


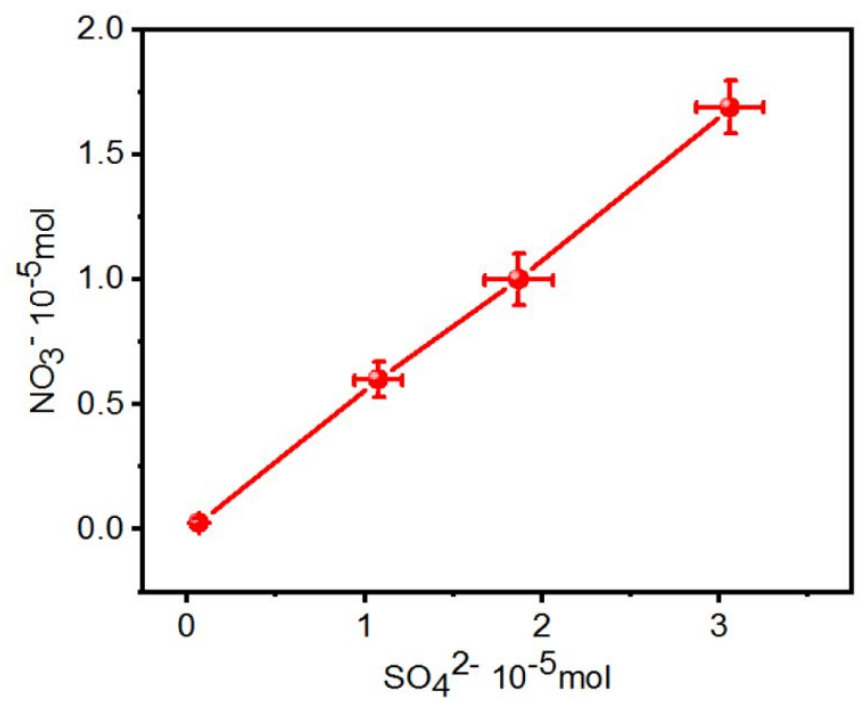

Figure S5. The amount of adsorbed $\mathrm{HNO}_{3}$ as function of the loaded sulfate on WISM $+\mathrm{SO}_{4}{ }^{2-}$ samples. The error bars were standard errors of the mean, obtained by repeating each experiment 3 times.

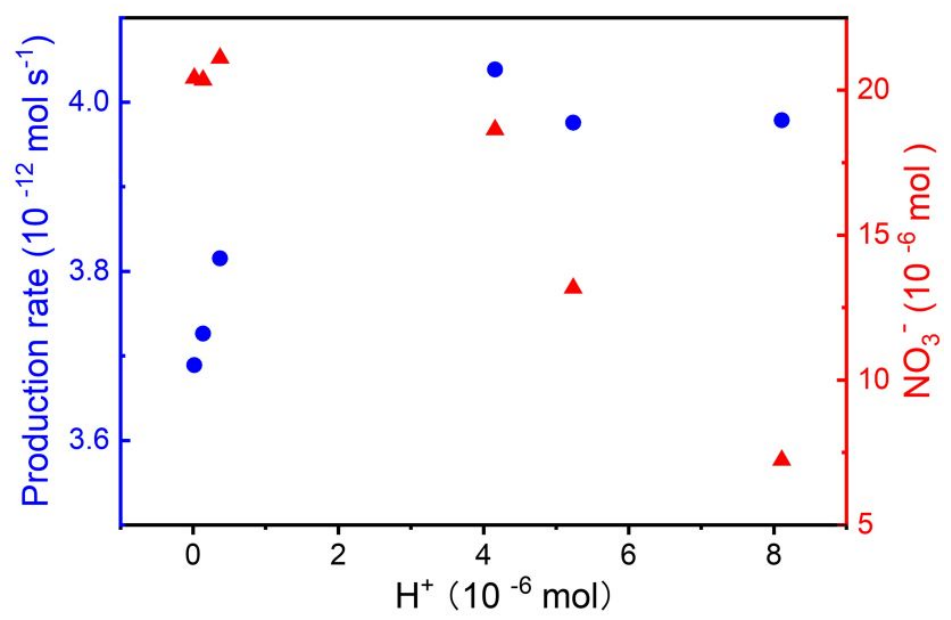

Figure S6. The total production rate of $\mathrm{HONO}$ and $\mathrm{NO}_{\mathrm{x}}$ of the photochemical reaction of $\mathrm{HNO}_{3} / \mathrm{NO}_{3}{ }^{-}$(left, blue) with WISM+$+\mathrm{SO}_{4}{ }^{2-}+\mathrm{NO}_{3}{ }^{-}$samples and their $\mathrm{NO}_{3}{ }^{-}$contents (right, red) as a function of their $\mathrm{H}^{+}$contents. The adsorption of gas-phase $\mathrm{HCl}$ would lead to the liberation of $\mathrm{HNO}_{3}$ to the gas phase, which depletes $\mathrm{NO}_{3}{ }^{-}$away from the WISM+$+\mathrm{SO}_{4}{ }^{2-}+\mathrm{NO}_{3}{ }^{-}$samples (right $\mathrm{Y}$ axis, red). However, even with lower amount of $\mathrm{NO}_{3}{ }^{-}$, the sample with more $\mathrm{H}^{+}$(more than $4.2 \times 10^{-6}$ mol) exhibited much higher 

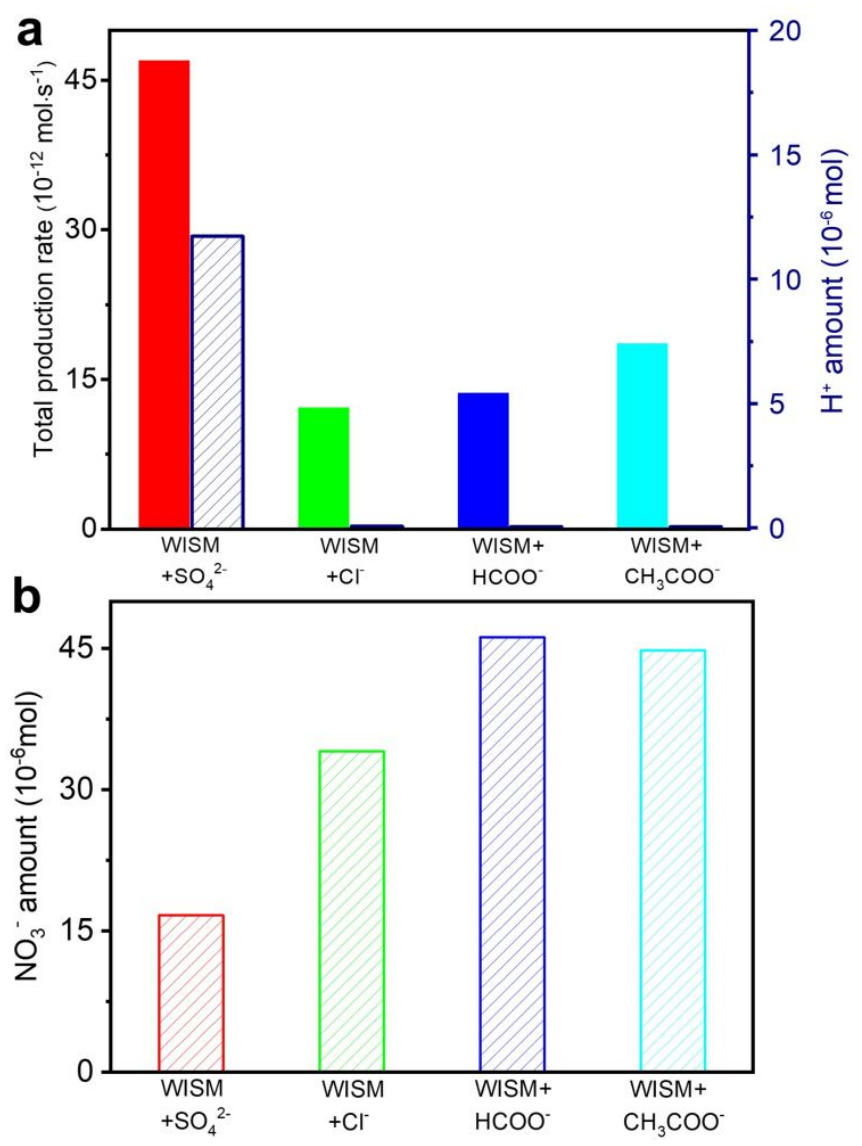

Figure S7. (a) The total production rate (solid bars, left axis) of $\mathrm{HONO}$ and $\mathrm{NO}_{\mathrm{x}}$ of the

57 photochemical reaction of $\mathrm{HNO}_{3} / \mathrm{NO}_{3}^{-}$with $\mathrm{WISM}+\mathrm{SO}_{4}{ }^{2-}$ (red), WISM+Cl- (green), WISM+HCOO (blue) and WISM $+\mathrm{CH}_{3} \mathrm{COO}^{-}$(cyan) samples at relative humidity of $90 \%$ and the corresponding amount of $\mathrm{H}^{+}$(patterned bars, right axis) and (b) the amount of adsorbed $\mathrm{NO}_{3}{ }^{-}$on these samples. 


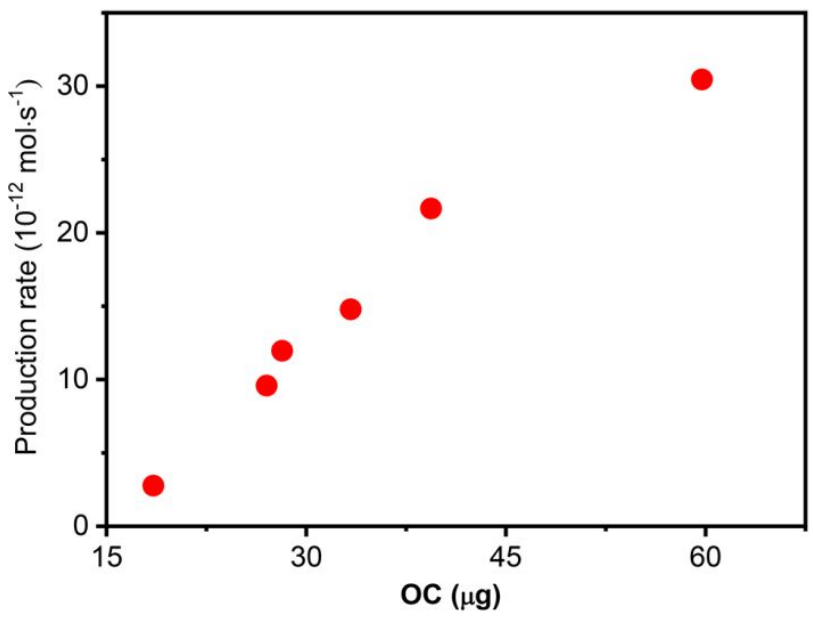

62 Figure S8. The total production rate of $\mathrm{HONO}$ and $\mathrm{NO}_{\mathrm{x}}$ of the photochemical reaction 63 of $\mathrm{HNO}_{3} / \mathrm{NO}_{3}{ }^{-}$with WISM+SO${ }_{4}{ }^{2-}$ samples (collected on different dates) as a function 64 of their organic carbon contents.

65

66 Table S1. Summary of the production rate of $\mathrm{NO}, \mathrm{NO}_{2}$, and $\mathrm{HONO}$ from

67 photochemical renoxification reactions with different samples.

\begin{tabular}{|c|c|c|c|c|c|}
\hline \multirow{2}{*}{\multicolumn{2}{|c|}{ Sample }} & \multicolumn{4}{|c|}{ Production rate $/ 10^{-12} \mathrm{~mol} \cdot \mathrm{s}^{-1}$} \\
\hline & & \multirow{2}{*}{$\frac{\boldsymbol{P}_{\mathrm{NO}}}{37.44}$} & \multirow{2}{*}{$\frac{\boldsymbol{P}_{\mathrm{NO} 2}}{11.04}$} & \multirow{2}{*}{$\frac{\boldsymbol{P}_{\text {HONO }}}{27.84}$} & \multirow{2}{*}{$\frac{P}{76.32}$} \\
\hline 1 & $\mathrm{PM}_{2.5}$ & & & & \\
\hline 2 & WISM & 0.19 & 0.29 & 0.01 & 0.49 \\
\hline 3 & WSM & 14.77 & 1.40 & 4.80 & 20.96 \\
\hline 4 & $\mathrm{WISM}+\mathrm{SO}_{4}^{2-}$ & 7.61 & 13.59 & 0.42 & 21.62 \\
\hline 5 & $\mathrm{WISM}+\mathrm{Cl}^{-}$ & 0.91 & 2.41 & 0.01 & 3.33 \\
\hline 6 & WISM+HCOO- & 0.91 & 2.83 & 0.03 & 3.77 \\
\hline 7 & $\mathrm{WISM}+\mathrm{CH}_{3} \mathrm{COO}^{-}$ & 1.05 & 4.32 & 0.02 & 5.39 \\
\hline 8 & $\mathrm{WISM}+\mathrm{PO}_{4}^{3-}$ & 4.78 & 21.38 & 0.42 & 26.58 \\
\hline 9 & $\mathrm{WISM}+\mathrm{CA}$ & 3.49 & 1.6 & 3.33 & 8.42 \\
\hline 10 & WISM+SA & 7.52 & 2.99 & 3.91 & 14.42 \\
\hline 11 & $\mathrm{WISM}+\mathrm{SO}_{4}{ }^{2-}+\mathrm{CA}$ & 23.13 & 5.93 & 31.19 & 60.25 \\
\hline
\end{tabular}




\begin{tabular}{l|l|llll}
12 & WISM+SO & \\
& $2-+\mathrm{SA}$ & 29.2 & 9.14 & 12.48 & 50.82 \\
13 & $\mathrm{SO}_{4}^{2-+\mathrm{CA}}$ & 0.48 & 0.43 & 0.17 & 1.08 \\
14 & $\mathrm{SO}_{4}^{2-+}$ & 0.38 & 0.53 & 0.27 & 1.18 \\
15 & $\mathrm{SO}_{4}^{2-+\mathrm{HA}}$ & 17.29 & 4.16 & 17.29 & 38.74 \\
\hline
\end{tabular}

